\title{
Barriers for Digital Transformation: The Role of Industry
}

\section{Henrik CJ Linderoth}

School of Engineering

Jönköping University

Jönköping, Sweden

Email: henrik.linderoth@ju.se

\section{Mattias Jacobsson}

School of Engineering

Jönköping University

Jönköping, Sweden

Email: mattias.jacobsson@ju.se

\section{Amany Elbanna}

School of Management

Royal Holloway University of London

Egham, UK

Email: amany.elbanna@rhul.ac.uk

\section{Abstract}

Limited attention has been paid to why certain industries, like the AEC (Architectural, Engineering and Construction), is lagging behind in digital transformation. The question can be raised if there are characteristics on industry level that constrain digital transformation? The aim of the paper is to explore how the interactions among four industry key actors; architects, clients, contractors and consultants shape industry characteristics and the options for digital transformation through adoption and use of digital technology. The aim will be achieved through a combination of individual- and focus group interviews with representatives of the key actor groups focused on how they perceive Building Information Modelling (BIM). It is concluded that the characteristics of the industry; the focus on practical day-to-day action, a heterogeneous client side who have difficulties in putting demands on contractors and sub-contractors due to lack of competencies, and a product that raise barriers for process innovations do effectively constrain digital transformation.

Keywords Industry analysis, Digitalization, Transformation, Building and Construction, ICT, Adoption 


\section{Introduction}

Digitalization is claimed to be one of the most prominent transformative forces in society. In an organizational context, digital transformation can be understood as the combined effects of digital innovations brining about novel actors and actor constellations, structures, practices, values or beliefs that change, threaten, replace, or complement existing rules of the game in organizations, ecosystems, industries or fields (Hinings et al. 2018: 53). A digital innovation is described as the use of digital technology in a wide range of innovations, where digital is understood as the conversion of analogue information into binary language understood by computers (Nambisan et al. 2017:224).

However, not all industries can undertake digital transformation effectively. For example, the AEC (Architectural, Engineering and Construction) the industry is claimed to considerably lag behind other industries in the uptake of digital technologies (Agrawal et al. 2016). For example, the transformative, or disruptive potential of Building Information Modelling (BIM), the most predominant technology influencing the AEC industry to date, has been discussed for more than a decade without a significant increase in its adoption rate (see e.g. Eastman et al., 2011). Thus, the question can be raised if there are some features, or characteristics of the AEC industry that constrain digital transformation?

In 2005 Chiasson and Davidson (2005) claimed that industry has received little attention in ISresearch when developing theory and stated that (2005:597): "By focusing only on the organizational context, researchers may overlook elements in the industry that facilitate or constrain actors' ITrelated actions". Still, how industry shape IS-/IT-/ICT-/digital-related activities has received some attention in IS-research. To provide some examples, Chatterjee et al. (2001) argued that firms in very dynamic industries, whose business processes and product/service offerings are highly digitizable, are likely to engage in seemingly continuous stream of IT deployments. By focusing on industry type (general manufacturing, high-tech, banking/finance, and retailing service), Yeh and Chang (2007) showed how industry affects the motivation of firms to adopt security countermeasures. Cho and Mathiasen (2007) showed, by applying Van de Ven's (2005) industry infrastructure framework, how the influence of different components of the industry infrastructure alters over time and how there is a necessity of engaging different stakeholders in order to develop and components in the industry infrastructure. In a study of adoption of internet-based innovations in two US industries, Melville and Ramirez (2008) showed that information processing requirements in an industry determines ITadoption and diffusion. Muhanna and Stoel (2010) showed that IT capability appeared to be more relevant for the firm value in high tech industries, by investigating the relationships between IT capability, IT spending and market value, and Joshi et al. (2018) investigated how systematic variation in IT governance disclosure was influenced by the strategic role of IT in an industry.

while these studies, in different ways, focus on how industry shapes IT-related actions, the majority of them can be seen as taking their point of departure in variance theories (Markus and Robey 1988), where they, to a lesser extent, focus on the underlying mechanisms shaping the characteristics of an industry and how these influence IT-related activities. Based on Scott et al. (2000), Chiasson and Davidson (2005) identified "factors" in the material and resource respectively the institutional environment that shape the features of an industry. These features are in turn assumed to influence IT-related activities. However, no further analysis was done of how the interactions among the "factors" shapes industry characteristics, which could give a deeper understanding of why IT-related activities are conducted in certain modes. Jacobsson et al. (2017), developed the Chiasson and Davidson (2005) framework further in order to explain how interactions between industry features shape IT-related actions in the building and construction industry. The overall conclusion in that study is that interaction patterns among elements in the market and production environment, as well as institutional actors shape the socio-cognitive environment, where meaning is made of ICT, which in turn shapes the adoption and deployment of ICT (Jacobsson et al. 2017). However, their focus of their paper (ibid) was only on one key actor group, the contractors. In order to enhance the understanding of how characteristics of an industry is shaped and how these characteristics influence ICT-related activities, the role of different key actors has to be investigated. Accordingly, the aim of the paper is to explore how the interactions among four industry key actors; architects, clients, contractors and consultants shape industry characteristics and the options for digital transformation through adoption and use of digital technology. The aim will be achieved by a combination of individual- and focus group interviews with representatives of the key actor groups focused on how they perceive barriers and driving forces for adoption and use of Building Information Modelling (BIM). 


\section{Building Information Modelling (BIM)}

At the bottom line, a building information model involves contains a combination of "objects" - vague and undefined, generic or product-specific, solid shapes or void-space oriented (like the shape of a room), that carry their geometry, relations and attributes. BIM design tools allow extraction of different views from a building model for drawing production and other uses. These different views are automatically consistent, being based on a single definition of each object instance. BIM software also defines objects parametrically; that is, the objects are defined as parameters and relations to other objects, so that if a related object is amended, dependent ones will automatically also change. Each model element can carry attributes for selecting and ordering them automatically, providing cost estimates as well as material tracking and ordering (Eastman et al. 2011). BIM use can be classified on a more conceptual level after its capabilities (see also Carlo et al. 2012). This is, BIM can be used for $3 \mathrm{D}$ visualization, analysis and simulation, co-ordination and communication, and data extraction and transfer. These capabilities are in turn build up by two underlying capabilities: object-based information and xyz co-ordination that helps to accurately triangulate the geometric position of each object in the design space. For example, visualization and the xyz co-ordination helps to accurately triangulate the geometric position of each object, and for example detect clashes between objects.

\section{Analysing Industry}

If industry is claimed to be an important element for the understanding of the deployment of ICT, a crucial question is how industry can be understood? When defining industry, a wide array of definitions can be identified depending on the perspective taken. With the focus on products, Porter's (1980) basic definition is that industry is a group of companies producing products that are close substitutes for each other. The point of departure for this perspective is similar to that of an organizational population, i.e. organizations facing similar environmental vulnerabilities that foster similarities in adaptive capabilities and structural form (Hannan and Freeman 1977). If other organizational populations and institutional actors are included in the analysis, industry can be considered as an organizational field (Scott et al. 2000), which according to DiMaggio and Powell (1983:148) includes "... those organizations that in aggregate, constitute a recognized area of institutional life: key suppliers, resources and product customers, regulatory agencies and other organizations that produce similar services or products."

Regardless of the perspective chosen, it is important to understand that what is seen as industry is not static (Chiasson and Davidsson 2005). One such example is the nowadays blurred boundaries between the telecom, computer, and entertainment industry. Thus, when studying how industry shapes ICT related activities, it is of crucial importance for future theorizing that authors states their view on industry (ibid). Thus, in this paper industry is briefly considered as an organizational field, because the paper takes its point of departure from studies originating from this perspective.

\subsection{The Building and Construction Industry}

Major characteristics of the building and construction industry are for example that relations among actors are characterised by short-term market-based interactions (Gann 1996; Dubois and Gadde 2002). It is driven by the lowest price tender policy; a focus on action and short-term gains in operations (Jacobsson and Linderoth 2010) which result in actors optimising their own processes instead of the construction process as a whole (Love et al. 1998). The optimization of actors' own processes can be seen as a consequence of another central feature that distinguishes the building and construction industry from other industries: the way power is distributed (Harty 2005). A construction project may be coordinated by one actor, for example the main contractor, but each one of the organizations involved in a project has its own influence on the project and bring its own expectations and working methods (ibid). Even if contractual obligations are the mainstay of the formal coordination in the industry, in practice these are hard to enforce, especially when the work is underway (Earl 1996).

By drawing on Chiasson and Davidson (2005), Porac et al. (1989), and Orlikowski and Gash (1994), Jacobsson et al. (2017) developed a framework for analysing the building and construction industry, in order to give a plausible answer to the question of why the industry looks and functions as it does, and how characteristics of industry shape the adoption and use of ICT. In the overall framework, the interplay between the market and production environment, and institutional actors, shape the sociocognitive environment. In this way ICT applications are given a meaning and made sense of in the socio-cognitive environment that in turns shape the adoption and use in certain directions (figure 1). 


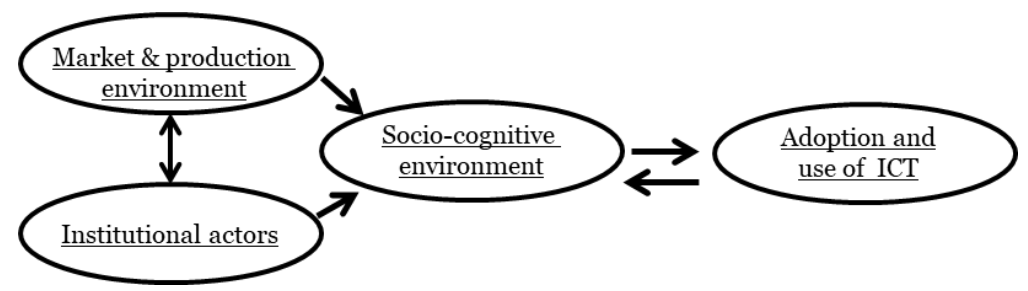

Figure 1: The shaping of adoption and use of ICT (Jacobsson et al. 2017)

The creation of the socio-cognitive environment, this is, the creation of interpretive frames that in turn shape the adoption and use of ICT, is furtherillustrated in figure 2. By starting the analysis in the market and production environment with demand-side factors, clients demand for unique designs and an immobile product imply that organising by projects becomes the most appropriate technology. Organizing by projects imply that time, cost, and scope will be of central importance in the governance system. While the project is a temporary endeavour governed by time, cost and scope, this does not imply per se that relations among actors in a project network become short-term and market-based. However, traditional demands from clients for a lowest price tender policy, force actors to form a project network with those who happen to have the lowest bid. This can be seen as a major reason for the short-term market-based relations characterising the industry. Thus, by drawing on Porac et al. (1989), it can be claimed that the focus on actions, in order to accomplish a project on time and within budget, is a central component in actors' interpretive frames regarding what it takes to compete successfully in the industry. These frames also have significant impact on the adoption and use of ICT, this is, benefits from ICT-use need to be fast and visible (Jacobsson and Linderoth, 2010). The focus on action is however not only present on the operational levels. Löwstedt and Räisänen (2014) describe how a practical and problem-solving focus, or "doer mentality", is a strong source of identity construction on all managerial levels in construction firms. In this sense, the client can be regarded as one of the most powerful institutional actor. As clients prioritise a lowest price tender policy, they reinforce both governance systems and short-term market-based relations among actors, and also the existing socio-cognitive environment where time and action are key characteristics.

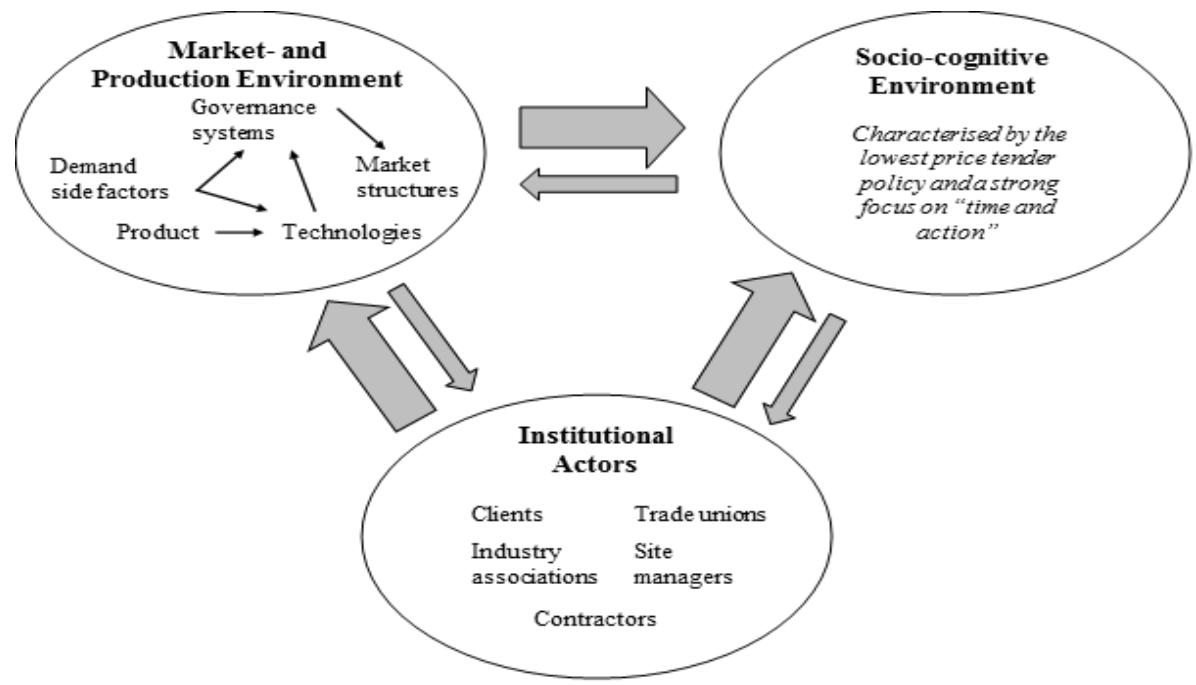

Figure 2: The creation of the socio-cognitive environment (Jacobsson et al. 2017)

Accordingly, the client and the product are central ingredients to understand how the characteristics of the building and construction industry have emerged over time. However, even if the client is powerful, its focus on investment costs is a bit paradoxical with regard to the life time of products and that the majority of costs are connected with operation and maintenance. Therefore, is it of interest to further investigate how the client view its operations and relations to other key actors in the industry. 


\section{Method and Data Collection}

This research takes its basis in a qualitative oriented research project targeting experienced representatives of the Swedish building and construction industry. The empirical material collected can be divided into two interrelated parts; semi-structured interviews and focus group interviews. Selection of respondents was primarily guided by willingness and commitment to participate. This was of great importance due to the integrated study design and the fact that interviewees were later invited to participate in the focus group interviews. Without willingness and commitment, the overall design would run the risk of failing (Krueger and Casey 2014; Dahlin-Ivanoff and Holmgren 2017).

In line with the study design, a total of 20 semi-structured interviews were conducted with four actor groups; clients, architects, contractors, and consultants. Five interviews were undertaken with each actor group. Adhering to common recommendations, all interviews was carried out at the office of the respondents to promote openness and familiarity (see e.g. Bryman and Bell 2015). The interviews were carried out between January 2017 and May of 2018 and totaled more than 30 hours, which corresponds to approximately 700 pages when transcribed. The transcribed interviews were sent out to each respondent for validation and approval. At the time of the interviews, the respondents had an average industry experience of over 23,5 years.

Following the semi-structured interviews, focus group interviews were undertaken in five rounds. Following the practical suggestions by Krueger and Casey (2014), we opted for a multiple-category design which provides a possibility to compare perspectives and ideas. The first four rounds were done with homogeneous groups in terms of the respondents being representatives from the same actor group. The fifth and final focus group interview were heterogeneous to its design in that it included one representative from each of the four actor groups. In line with the general rationale behind conducting focus group interviews, all respondents were presented with a specific theme (DahlinIvanoff and Holmgren 2017). The theme for the first four rounds related to the actors' views of existing barriers and drivers identified via the interviews, whitest the fifth focus group targeted possible solutions. In simple terms, one could argue that the first four rounds were problem oriented, whilst the final round was solution oriented. In essence, the focus group interviews complemented the semi structured interviews as they gave us an opportunity make sense of the identified barriers, and constructing meaning around it (Bryman and Bell 2015).

\section{A Short-Sighted Practice Based Industry}

In this section, the adoption and use of BIM and other digital technologies among the four industrial key actors will be described. In order to get an initial understanding of the adoption and use, key actors' perceptions of their daily operations and their interactions among each other will also be described. A major observation from the individual- and the focus group interviews is a perceived time pressure at all stages of the process, that is one constraint for exploring and exploiting BIM. In the following sub-sections, the major focus will be on the client and the contractor, for the simple reason that these are the two most powerful actors.

\subsection{Client - BIM, What's in It for Us?}

In the interviews and in the focus group with the client representatives, they were a bit ambivalent towards BIM. They see the benefits with clash controls in the detailed design stage, but when it comes to facility management they find it harder to see direct benefits. The project manager for the commercial facility management company express, however, some visions in the mixed focus group interview;

"The dream scenario for me, linked to digitalization and BIM and all this, it is, I think we should do life cycle analysis on all our buildings before we start [to build]. How we do that? No idea? But if we have all the conditions ready and build virtual, completely, three, four models, then we could do calculation on, in principal, everything... and then chose one of the models"

In the individual interviews and in the focus group interviews, there are not many concrete ideas expressed about the practical BIM use. But the managing director for the municipal housing company has become very positive towards BIM on the general level. Even if both companies do not have any digitalized information models of their buildings, they are highly digitalized in other areas. Both companies have very good control of the operation of the buildings. If an error occurs with some equipment, the janitor on duty get an alarm about what is malfunctioning. The facility manager for the housing company further state that they have very good control over what they have in the apartments. 
They know when they have put new wallpaper in the rooms, how old the stoves are, and they can control ventilation and the temperature in the apartments. Managers from both companies further state that they get a lot of operational data from their facilities, but they never do any meta-analysis of the data. Thus, in both companies, most buildings are on-line in the sense that the operation of the buildings can be remotely controlled. The housing company also have rather encompassing information about the status of equipment in the apartments. When it comes to information about the physical building, the access to information is however rather poor. When the question is asked if they know how many windows there are and what features the windows have, in case they should change the windows in the buildings in a residential area, the manager laughs in response. He then explains that they send a janitor out to count the windows, because they should also have something to do! Moreover, the representatives for both companies confess that it is very difficult to get some good structure of the drawings of the buildings. One interviewee state that they lost the control when CAD appeared and they got the drawings on CD's. The facility manager explains that they had better control over drawings when they were on paper and put into binders.

The degree of digitalization of facility information can, however, be seen a bit paradoxical regarding the trust in the systems. On one side, both companies' facilities are more or less on-line with regard to operation of the facility and the housing company has systems for controlling the information about the status of the apartments and their equipment. On the other side, when BIM and the information about the physical building is discussed, a scepticism arises connected to the time horizon. The head of facility management states that their time perspective is 50 to 100 years, whereas in the IT-industry the time perspective might be one to two years, so he asks if it is possible to retrieve the information 10 years later? Another concern he raised is the investment of time:

"If we should implement new systems like BIM, I feel that we must learn how it's functioning, but it might take ten years until we get some use for it. It's a big investment of time."

The major reason mentioned for not having time to invest in learning new technologies is the daily operations. The facility manager claims that they deal with many daily happenings and emergencies in the 8 ooo apartments they have. However, the managing director for the municipal housing company suggests that it might be easier to focus on the practical things in the daily operations:

"It's damn good when it's snowing. Everyone knows what they should do. Now it's snowing, it is wonderful, so to say. But if nothing is happening, what should I do then? How should I then anticipate things? So that I don't end up in troubles later?"

It is furthermore discussed if the excuse that there is a "lack of time" is just a defence mechanism because of a lacking of knowledge? One participant in the group interview states that people tend to prioritize less important, but urgent tasks before tasked that are important but less urgent. All participants in the group agree that there is a lack of competencies in the organization to explore new technologies. The managing director asks rhetorically how they can take advantage of BIM in a way that helps a janitor in his/her daily work? Another problem stressed by the managing director is the need for integrating all the different parts of the company before they can gain more power in their relations to the contractors. There are four major areas that have to be integrated: market, property development, technical support and facility management. In addition, they have four different districts for facility management with four managers who have their own ideas, as well as they have four project managers for property development who also have their own ideas about the operations. Moreover, the head of property development state that a former managing director thought that it was a problem if representatives for facility management was involved in the project development. He argued that they should not be allowed to have any influence on the construction of the buildings they would later on manage.

Furthermore, the representative for the commercial company states that there is a lack of understanding of the construction process from the tenants, even if he tries to be as pedagogical as possible and explain why things takes time. He states that people understand and accept that it takes time if windows cannot be delivered in 10-12 weeks, but other things that takes time, people neither understand nor accept. In the focus group with all four key actors, the client and contractor representative agreed that they are co-producing the time pressure. The client promises the potential tenant that the facilities can be available at a certain date. At the same time the contractor, who is time optimistic, promise to build the facilities on a tight time schedule. This will in turn put pressure on architect and consultants to speed up the process, which leads to a product with low quality. 


\subsection{Contractor - BIM, a Means for Internal Efficiency}

During the interviews with representatives for the large contractor, it is revealed that they have managed to mobilize a stable "core" network where BIM is used. However, four of the interviewees, who works more or less close with BIM, state that the challenge is still to convince the very large majority about the advantages. A BIM-coordinator who manages the detailed design states that:

"...in the detailed design, the revolution has already occurred, I think. Because even if we order a 2D-project today, we will in the most cases model it [...] in that way we achieve a much better quality assurance [...] but we have not reached out to the production. That is the big challenge. It is 'damned' difficult for us to answer what's wrong."

The BIM-coordinator further states that the higher-level management see BIM as an issue of strategic importance. They are pushing for it and investing money in it. Then there is a layer of "BIM workers" who are rather knowledgeable and know how to work with BIM. But all four of the interviewees state that the middle management lacks knowledge about how BIM can develop operations. This view is partly confirmed when a middle manager for another large contractor is interviewed. He states that BIM is used in many projects, that it fills it purposes, and that they have a special group working with these issues. But he does not have so much more to say about BIM. Moreover, in the focus group interview it is also stated that the way BIM is used varies a lot between different locations and is dependent on enthusiastic individuals.

Beyond the top management willingness to support BIM-use with investments, additional initiatives are also taken. One such initiative is that the company each year has sent a number of employees to courses where they get training in working with BIM. In addition, based on the BIM-training, manuals for how to work with BIM has been developed where requirements are described for how to work with BIM, depending on how encompassing the BIM use should be in a project. The manuals function as support for the BIM coordinators when structuring the work, but a group of BIM "super users" is also established in order to modify manuals based on feedback from the projects. When working with BIM, one key activity is to work in BIM-studios, that basically is a kind of concurrent engineering. The BIM coordinators interviewed state that some senior consultant had difficulties in accepting the new roles of being present and working a whole day together with other consultants. But it is getting more and more accepted, and now at least the junior consultants stay for the whole day.

However, interviewees working with BIM states that there are some problems internally to get people to re-think how to work. A site manager says that they should build in the model and assemble on site. This claim has been rathercontroversial, because opponents' question what happens to the labour skills. But the site manager states that site worker just have to do things one time, instead of two when things go wrong. A BIM coordinator further relates this idea with an improved psycho-social work environment for site managers. He states that by solving as many problems as possible in the modelling stage, this would reduce the stress for site managers in the production stage. At the same time the manager states that they internally need to fight for getting enough time for preparing the detailed design. He says that if they get a contract on Friday, people want to start to build the week after. He explains that a number of issues have to be resolved before they can start to build:

"First, we need to procure a structural engineer, we have to go with the architect through what we want to do. We need to procure sub-contractors for field installations, we have to investigate the building together with them and see what questions they have. Maybe they were procured on a price per square meter. So, this is a very complex process, and it is not even understood internally in the contractor company, I believe. It's more like; why haven't we started yet out there? We signed the contract on Friday, today is Monday."

In the focus group interview with the contractors, they are asked about the biggest barriers for the information flow between the partners in the process. A site manager states rather quickly that the type of contract has the biggest influence, because it is where the money is:

"If you have a design - bid - build contract, you don't give more information than necessary, because you can get paid extra for it. If it is a design - build contract, you don't give more information than you get paid for. But if it is a partnering contract you get paid for sharing information." 


\subsection{Consultants - BIM, Not a Big Issue}

The consultants have no joint view about BIM, more than it seems that consultants prefer another software than architects, which could lead to compatibility problems in the projects. The major reason is that different software fit, more or less, better for the different consultant groups. However, the responsible for IT, hardware and software, in one of the companies states that it has been a very rapid development in the last five years and the tools in the different software becomes more and more compatible.

As well as the architects and contractors, the consultants have opinions about the clients' long-term considerations. The senior consultants say that the documentation of information about the physical building is very poor. Especially if it is taken into consideration that the value of the buildings is rather high. The consultants think it would be in the interest of facility management to have total control over the building, by using systems to manage the information. A consultant says it would be possible to get information about how many light bulbs there are in a building by just pressing a button, or which material it is in the building and how everything looks like. But in the focus group interview, the opposite situation is described. One consultant says that even big clients sometimes implicitly expects that the consultants keep the drawings of the buildings, but when they (clients) come back twenty years later, the drawings are gone, and noting is regulated by contractual agreements.

The consultants also commented on the existing action mentality in the industry. A consultant gives the following example:

"You can get a phone call on Friday afternoon. 'We are working with the surveying and something is wrong'. Then you talk with someone, they are so upset and they screaming. It goes a while, you ask someone to contact them [with the problem], then it is no problem, everything is clear. But you start with screaming as your life were in danger. Then I think: calm down first."

The consultants also stress the problems when a client tries to save money in the early stages of a project. One consultant state:

“... it will be wrong if you in the detailed design tries to save money by decreasing the time for the detailed design, because you think you can save money. In many cases the problems are coming anyhow, and it will be more expensive to fix them. And if you come to the facility management stage it will be even more expensive[...] But we might be bad at selling the idea, or we don't have time, because we are fully occupied."

Another issue that is discussed in the focus group is the need for knowledge and experience, and the lack of experienced consultants in different fields. One problem identified is that younger consultants do not have the necessary knowledge and experience, for obvious reasons, but they are very skilled in using new IT-tools, whereas the experienced consultants are not very skilled in using new IT-tools. One consultant state that the dream scenario would be if they could bring together these two competencies, which would leverage the performance of the industry.

\subsection{Architects - Pay Us for Using it More}

BIM has become the normal way of working among the architects with regard to information content. An architect interviewed state that there are only three people in their office who still have a drawing table, whereas in other architect offices there are no drawing tables left. The importance of working with BIM is further emphasized by the most experienced architect interviewed, who is close to retirement. He states that he nowadays feels incompetent when he wants to proceed from the sketching stage, because younger colleagues always have to help him.

However, when it comes to a more advanced use of BIM, for example adding more information to the model, the architects state that there is a lack of willingness among the clients to pay for the extra time required to add the information. One architect state that it is a long pedagogical journey to convince the client that they can use a model containing information about the facility. Another architect state that some clients understanding about what digital information is differs significantly from the architects understanding. For example, they are doubtful when the municipality consider digitalized 2D drawings as digitalization. The architects further state that the municipality work with very oldfashioned systems, and it is hard to convince them of the advantages of BIM. But one of the biggest problems identified by the architects is that the consultant with the lowest technical standard defines how (non)advanced the use of BIM can be in a project. 
A further issue is the ownership of the model. The head of an architect office states that in many contracts with contractors, they must transfer the ownership of the model to the contractor. The architect questions what the contractor should do with the ownership and their legal adviser is not happy with that solution. The architects understand that contractors want the information in the model but questions why they should waive not only the artistic right, but also the rights to the whole solution. Moreover, the architects are also very frustrated of the cases when contractors switch architect during the process, because then the architect is losing control over the end product. In the interviews with the contractor, they say ownership is not an issue, it is stated in their BIM rules that they should own the model, if they want to change to another architect for some reason.

Common for the architects interviewed is that they feel cut off in the process and they are considered as someone just producing an attractive design. They state that they can contribute with much more knowledge in the process and add more holistic perspectives. One architect says that contractors are just interested in how they can build a house as efficient as possible, whereas the architects takes the whole urban space into consideration. During the interview it is also obvious that the architects in Sweden has a different (lower) status compared to other European countries where the architect has a much more central role during the whole building process. This is, in some European countries they have much more power and control over the final product, which their Swedish colleagues does not have. During the interviews a slight sign of frustration is noticed, when some architects state that their level of education is generally higher than the other key actors', and the architects have lot of ideas how BIM could be beneficial for the client, but clients do not want to pay for the extra time it takes to add more information into a model. This is, the clients do not see the benefits.

\section{Concluding Discussion}

The aim of the paper has been to explore how the interactions among four industry key actors; architects, clients, contractors and consultants shape industry characteristics and the options for digital transformation through adoption and deployment of digital technology. The result from the study confirms earlier observations that the project-based parts of the industry is highly action oriented and if innovations should be accepted, results has to be fast and visible (see Jacobsson and Linderoth 2010). But what has been less highlighted in previous studies and becomes obvious in this study, is the action orientation in the facility management part of the industry, this is, the focus on the "practical doings" in the daily work. This has also had consequences for the adoption and use of ICT. When clients in the study are closely scrutinized, it is revealed that their facilities are more or less online by monitoring them with a wide range of different sensors and alarms. This kind of information transfer is well aligned with the action orientation. The (financial) consequences are quite immediate if no one reacts on an alarm. The same logic can also be claimed to be behind the rather good control of the information about the conditions of equipments in apartments. The underlying reason for this is that most real estate companies have certain policies for when equipment should be changed and when apartments should be renovated. Hence, access to reliable information eases the argumentation with tenants' whether an apartment should be renovated, or if equipment should be changed. The consequences of not having this kind of information can be compared with the consequences of lack of control in other facility related information. For example when a drawing is missing. time will be spent for searching the drawing, but there are no immediate financial consequences in terms of an invoice from a supplier. Thus, even if technologies like BIM are recognized to have a wide variety of potential applications in facility management, the technology is not widely used in practice (see Pärn et.al. 2017) because it is difficult to see the immediate financial benefits. This focus on information connected to the practical day-to-day activities implies a low perceived need for information about the physical building, and information that is more rarely used. Thus, when the facility management is involved in the early stages of a project, the focus will be more on the implications of they lay-out of a physical building, then the eventual information content in a BIM-model.

The issue is where this focus on action in the daily practice is coming from? One plausible explanation might be given by the architects, when they state that there are differences in levels of education among the key actors in the industry. It can be argued that practice-based actors have their focus on what is happening in the day-to-day operations. In this sense it is also easier to understand, adopt and use ICT where the applications are rather practice based, instead of thinking about how new ICT, like BIM could redefine the business logic in the industry. However, this condition does not explain, why the [top] management do not think strategically about digital technologies like BIM. The question can be raised if managers in facility management companies have the same mental frames as managers in contractor firms, where a practical and problem-solving orientation is a strong source of identity construction on all managerial levels (see Löfstedt and Räisänen 2014). 
Another potential barrier for digital transformation is the immobility of products that more or less reduces the pressure for process innovation. This is, contractor firms can buy material on a global market, but the assembly of the products is bounded to a specific physical location. This implies that there is a potential correlation between the size of the projects and the number of contractors who potentially have an interest in the project. Thus, there is a global competition for mega projects, but until present date, this situation has not increased the pressure for process innovation by means of digital transformation in order to stay competitive. Moreover, due to very heterogeneous client side, there is no rigid standard processes to be followed. Contractors, architects, and consultants constantly returning to the clients' lack of knowledge, or competence. Both with regard to what the construction process looks like, but also with regard to the client's knowledge about what it wants. The client organizations in the study may not be typical client organizations, because they are rather big, they have a rather high volume of construction projects, and they also have project managers with a contractor background in order to have the right competence to control contractors. Nevertheless, the representatives for the client organization do complain about an internal fragmentation and a lack of understanding for what others in the organization are doing. As the managing director for municipal housing company stated, it is their biggest challenge to be better integrated internally if they should be an even more professional client and be able to take the lead over the contractors. Against this background it is hardly surprising that a technology like BIM not has reached the expected break through. The basic idea behind BIM is a seamless information flow from the very early stages of the process to the demolition, or conservation of a building, which requires a client with very clear ideas of what kind of information they want in the models and who also have the power and knowledge to put the demands on contractors and sub-contractors.

To conclude, the characteristics of the industry, this is, the focus on practical day-to-day action, a heterogeneous client side who have difficulties in putting demands on contractors and sub-contractors due to lack of competencies, and a product that raise barriers for process innovations, do effectively constrain digital transformation. This is, the combined effects of digital innovations brining about novel actors and actor constellations, structures, practices, values and beliefs that change, threaten, replace or complement existing rules of the game with in organizations, ecosystems, industries or fields (Hinings et al. 2018: 53).

\section{References}

Agarwal, R., Chandrasekaran, S., and Sridhar, M. 2016. "Imagining construction's digital future", https://www.mckinsey.com/industries/capital-projects-and-infrastructure/ourinsights/imagining-constructions-digital-future. Retrieved Oct 18.th 2018.

Bryman, A., and Bell, E. 2015. Business research methods. USA: Oxford University Press.

Carlo, J. L., Lyytinen, K. and Boland Jr., R.J. 2012. "Dialectics of collective minding: Contradictory appropriations of information technology in a high-risk project," MIS Quarterly, (36:4), pp 1081-1108.

Chatterjee, D., Richardson, V. J. and Zmud, R. W. 2001. "Examining the shareholder wealth effects of announcements of newly created CIO positions," MIS Quarterly, (25:1), pp 43-70.

Chiasson, M., and Davidson, E. 2005. "Taking industry seriously in IS research," MIS Quarterly, (29:1), 2-16.

Cho, S. and Mathiasen, L. 2007. "The role of industry infrastructure in telehealth innovations: a multilevel analysis of a telestroke program," European Journal of Information Systems, (16:6), pp 738-750.

Dahlin-Ivanoff, S., and Holmgren, K. 2017. Fokusgrupper. Lund: Studentlitteratur.

DiMaggio, P. J. and Powell, W. W. 1983. "The iron cage revisited: Institutional isomorphism and collective rationality in organizational fields," American sociological review, (48:2), pp 147160.

Dubois, A. and Gadde, L. E. 2002. "The construction industry as loosely coupled system: implication for productivity and innovation," Construction Management and Economics, (20:7), pp 621631.

Earl, P. 1996. "Contracts, coordination, and the construction industry", in Management, marketing and the competitive process, in P. Earl, Cheltenham: Edward Elgar. 
Eastman, C. M., Teicholz, P., Sacks, R. and Liston, K. 2011. BIM handbook: A guide to building information modelling for owners, managers, designers, engineers and contractors. John, Hoboken, NJ: Wiley \& Sons.

Gann, D. M. 1996. "Construction as a manufacturing process? Similarities and differences between industrialized housing and car production in Japan", Construction Management and Economics, (14:5), pp 437-445.

Hannan, M. T. and Freeman, J. 1977. "The population ecology of organizations," American Journal of Sociology, (82:5), pp 929-964.

Harty, C. 2005. "Innovation in construction: a sociology of technology approach", Building research \& Information, (33:6), pp 512-522.

Hinings, B, Gegenhuber, T., and Greenwood, R. 2018. "Digital innovation and transformation: An institutional perspective," Information and Organization, (28:1), pp 52-61.

Jacobsson, M. and Linderoth, C. J. H. 2010. "The Influence of Contextual Elements, Actors' Frames of Reference and Technology on the Adoption and Use of ICT in Construction Projects: a Swedish Case Study", Construction Management and Economics, (28:1), pp 13-23.

Jacobsson, M., Linderoth, H. C., and Rowlinson, S. 2017. "The role of industry: an analytical framework to understand ICT transformation within the AEC industry," Construction Management and Economics, (35:10), pp 611-626.

Joshi, A., Bollen, L., Hassink, H., De Haes, S., and Van Grembergen, W. 2018. "Explaining IT governance disclosure through the constructs of IT governance maturity and IT strategic role," Information and Management, (55:3), pp 368-380.

Krueger, R. A., and Casey, M. A. 2014. Focus groups: A practical guide for applied research. USA: Sage publications.

Love, P., Gunasekaran, A. and Li, H. 1998. "Concurrent engineering: a strategy for procuring construction projects," International Journal of Project Management, (16:6), pp 375-383.

Löwstedt, M. and Räisänen, C. 2014. "Social identity in construction: Enactments and outcomes". Construction Management and Economics, (32:11), pp 1093-1105.

Markus, M. L., and Robey, D. 1988. "Information technology and organizational change: causal structure in theory and research," Management science, (34:5), pp 583-598.

Melwille, N. and Ramirez, R. 2008. "Information technology innovation diffusion: an information requirements paradigm," Information Systems Journal, (18:3), pp 247-273.

Muhanna, W. A. and Stoel, M. D. 2010. "How Do Investors Value IT? An Empirical Investigation of the Value Relevance of IT Capability and IT Spending Across Industries", Journal of Information Systems, (24:1), pp 43-66.

Nambisan, S., Lyytinen, K., Majchrzak, A., and Song, M. 2017. "Digital innovation management: Reinventing innovation management research in a digital world," MIS Quarterly, 41, 223-236.

Orlikowski, W. J. and Gash, D. C. 1994. "Technological frames: Making sense of information technology in organizations", ACM Transactions on information systems, (12:2), pp. 174-207.

Pärn, E. A., Edwards, D. J., and Sing, M. C. P. 2017. "The building information modelling trajectory in facilities management: A review," Automation in Construction, (75), 45-55.

Porac, J. F., Thomas, H., Baden-Fuller, C. 1989. "Competitive Groups as Cognitive Com-munities: The case of Scottish knitwear manufacturers," Journal of Management Studies, (26:4), 397-416.

Porter, M. 1980. Competitive strategy, New York: The Free Press.

Scott, W. R., Ruef, M., Mendel, P. and Caronna, C. 200o. Institutional change and healthcare organizations: From professional dominance to managed care, Chicago: Chicago University Press.

Van de Ven, A. H. 2005. "Running in packs to develop knowledge-intensive technologies," MIS Quarterly, (29:2), pp 365-377.

Yeh, Q. J., and Chang, A. J. T. 2007. "Threats and countermeasures for information system security: A cross-industry study," Information \& Management, (44:5), pp 480-491. 


\section{Acknowledgements}

The authors want to thank Jönköpings läns byggmästareförening and Smart Built Environment who financed the study.

\section{Copyright}

The following copyright paragraph must be appended to the paper. Author names MUST not be included until after reviewing. Please ensure the hyperlink remains for electronic harvesting of copyright restrictions.

Copyright: (C) Henrik Linderoth, Mattias Jacobsson, and Amany Elbanna. This is an open-access article distributed under the terms of the Creative Commons Attribution-NonCommercial 3.0 Australia License, which permits non-commercial use, distribution, and reproduction in any medium, provided the original author and ACIS are credited. 